\title{
ANALISIS STRATEGI BISNIS PT. TOLU DENGAN PENDEKATAN BMC MENGGUNAKAN METODE EFAS, IFAS DAN SWOT
}

\author{
${ }^{1}$ Riamande Jelita Tambunan, ${ }^{2}$ Dewi Agushinta R. \\ ${ }^{1}$ Magister Manajemen Sistem Informasi, Sistem Informasi Bisnis \\ Program Pascasarjana Magister Teknologi dan Rekayasa \\ ${ }^{2}$ Sistem Informasi, Fakultas Ilmu Komputer dan Teknologi Informasi \\ Universitas Gunadarma \\ Email: riajelita@gmail.com,dewiar@staff.gunadarma.ac.id
}

(diterima: 11 Februari 2020 ,direvisi: 10 Maret 2020, disetujui: 19 Juli 2020)

\begin{abstract}
PT. Tolu Tiopan Tondi (PT. Tolu) is a company engaged in the manufacture of furniture. Standards and product quality can be maintained by the company to meet consumer needs. But with so many business ventures in the same field, PT. Tolu must understand and have plan business strategies to continue to compete in the business world and still get full trust from customers as one of the company's survival guarantees. So that the business of PT. Tolu grows and recognized by the wider community, it is necessary to plan a business strategy. PT. Tolu uses a Business Model Canvas (BMC) approach that can develop business strategies for the present as well as the future to analyse the business strategy. The results of the analysis of the existing business strategy indicate that the strategy used by PT. Tolu is included in the criteria of feasible. It means that the organization is in prime and steady condition. It is possible to continue to expand, enlarge growth and achieve maximum progress. Based on the results of the analysis the development of the business model canvas is carried out on the channel component, key resource component, and customer relationship component.
\end{abstract}

Keywords: business model canvas, EFAS, IFAS, SWOT

\begin{abstract}
ABSTRAK
PT. Tolu Tiopan Tondi (PT. Tolu) merupakan perusahaan di bidang pembuatan furnitur. Standar dan kualitas produk mampu dipertahankan perusahaan tersebut untuk memenuhi kebutuhan konsumen. Namun dengan banyaknya usaha bisnis di bidang yang sama, PT. Tolu harus memahami serta merencanakan strategi bisnis agar dapat terus bersaing dalam dunia bisnis dan tetap mendapat kepercayaan penuh dari pelanggan sebagai salah satu jaminan kelangsungan hidup perusahaan. Agar bisnis PT. Tolu berkembang dan semakin dikenal oleh masyarakat luas, maka perlu direncanakan strategi bisnis. Untuk menganalisis strategi bisnis PT. Tolu menggunakan pendekatan Business Model Canvas yang dapat mengembangkan strategi bisnis untuk masa sekarang maupun masa yang akan datang. Hasil analisis terhadap strategi bisnis eksisting menunjukkan bahwa strategi yang digunakan oleh PT. Tolu termasuk dalam kriteria "layak" artinya organisasi dalam kondisi prima dan mantap sehingga benar-benar dimungkinkan untuk terus menjalankan ekspansi, memperbesar pertumbuhan dan meraih kemajuan secara maksimal. Hasil analisis menunjukkan perlu dilakukan pengembangan pada Business Model Canvas yaitu pada komponen channel, key resource dan dengan menambahkan website untuk memasarkan produk agar lebih dikenal masyarakat luas customer relationship.
\end{abstract}

Kata Kunci: business model canvas, EFAS, IFAS, SWOT

\section{PENDAHULUAN}

Data Badan Pusat Statistik memperlihatkan, perkembangan usaha kecil dan menengah di Indonesia semakin meningkat. Tercatat pasca krisis ekonomi tahun 1997-1998 jumlah usaha kecil dan menengah tidak berkurang, justru mengalami peningkatan, bahkan mampu menyerap 85 juta hingga 114 juta tenaga kerja sampai tahun 2013 [1]. Sementara itu, dengan pesatnya pertumbuhan usaha kecil 
dan menengah ditambah dengan tipe bisnis yang sama meningkat, persaingan akan semakin ketat dan itu bisa menyebabkan kerugian dan kebangkrutan.

PT. Tolu Tiopan Tondi (PT. Tolu) merupakan perusahaan yang bergerak di bidang pembuatan mebel. Standar dan kualitas produk mampu dipertahankan perusahaan tersebut untuk memenuhi kebutuhan konsumen. Namun dengan banyaknya usaha bisnis di bidang yang sama, perusahaan harus lebih memperhatikan lingkungan yang dapat mempengaruhi perusahaan, agar perusahaan mengetahui strategi pemasaran seperti apa dan bagaimana yang harus diterapkan dalam perusahaan. PT. Tolu harus memahami serta merencanakan strategi bisnis agar dapat terus bersaing dalam dunia bisnis dan tetap mendapat kepercayaan penuh dari pelanggan sebagai salah satu jaminan kelangsungan hidup perusahaan.

Business Model Canvas (BMC) merupakan salah satu alat strategi yang digunakan untuk mendeskripsikan sebuah model bisnis dan menggambarkan dasar pemikiran tentang bagaimana organisasi menciptakan, memberikan, dan menangkap nilai serta membantu melihat lebih akurat rupa usaha yang sedang atau yang akan kita jalani [2].

Perencanaan strategi bisnis diperlukan agar bisnis PT. Tolu berkembang dan semakin dikenal oleh masyarakat luas. Untuk menganalisis strategi bisnis, PT. Tolu menggunakan pendekatan Business Model Canvas yang diharapkan dapat mengembangkan strategi bisnis untuk masa sekarang maupun masa yang akan datang. Penelitian ini bertujuan untuk mengidentifikasi, menganalisis dan mengembangkan model bisnis pada PT. Tolu dengan pendekatan Business Model Canvas. Setelah mengidentifikasi Business Model Canvas, maka akan dilakukan analisis pada setiap elemen yang terdiri dari customer segments, value propositions, channels, customer relationship, revenue streams, key resources, key activities, key partnership, dan cost structure, dengan analisis SWOT.

\section{TINJAUAN PUSTAKA}

Manajemen strategi dapat didefinisikan sebagai seni dan pengetahuan dalam merumuskan, mengimplementasikan serta mengevaluasi keputusan-keputusan lintas fungsional yang memampukan sebuah organisasi mencapai tujuannya. Sebagaimana disiratkan dalam definisi ini, manajemen strategi berfokus pada usaha untuk mengintegrasikan manajemen, pemasaran, keuangan/ akuntansi, produksi/ operasi, penelitian dan pengembangan, serta sistem informasi komputer untuk mencapai keberhasilan suatu organisasional [3].

Strategi bersaing adalah penetapan sasaran dan tujuan jangka panjang sebuah perusahaan, dan arah tindakan serta alokasi sumber daya yang diperlukan untuk mencapai sasaran dan tujuan tertentu [4].

Business Model Canvas (BMC) salah satu alat strategi yang digunakan untuk mendeskripsikan sebuah model bisnis dan menggambarkan dasar pemikiran tentang bagaimana organisasi menciptakan, memberikan, dan menangkap nilai. Business Model Generation, lebih populer dengan sebutan Business Model Canvas adalah suatu alat untuk membantu kita melihat lebih akurat rupa usaha yang sedang atau kita akan jalani. Mengubah konsep bisnis rumit menjadi sederhana yang ditampilkan pada satu lembar kanvas berisi rencana bisnis dengan sembilan elemen kunci yang terintegrasi dengan baik di dalamnya mencakup analisis strategi secara internal maupun eksternal perusahaan [2]. Gambar 1 berikut merupakan 9 (sembilan) blok Business Model Canvas.

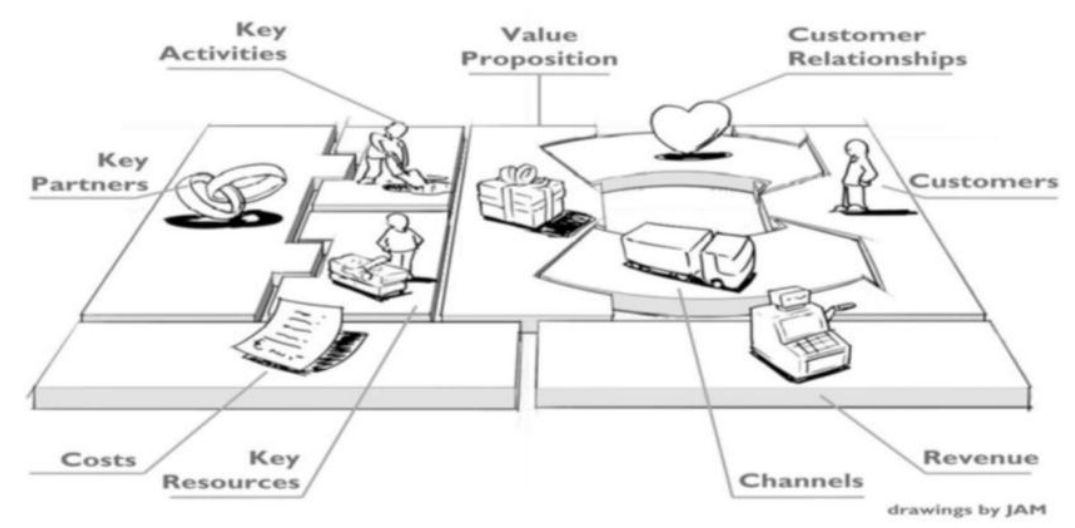

Gambar 1. Blok Business Model Canvas [2] 
Customer Segment (segmen pelanggan): blok bangunan yang menggambarkan sekelompok orang atau organisasi berbeda yang ingin dijangkau atau dilayani oleh perusahaan. Pelanggan adalah inti dari semua model bisnis. Tanpa pelanggan (yang dapat memberikan keuntungan), tidak ada perusahaan yang mampu bertahan dalam waktu lama.

Value Propositions (proposisi nilai): blok bangunan yang menggambarkan gabungan antara produk dan layanan yang menciptakan nilai untuk segmen pelanggan spesifik. Proposisi nilai dapat memecah masalah pelanggan atau memuaskan kebutuhan pelanggan.

Channels (saluran): blok bangunan yang menggambarkan bagaimana sebuah perusahaan berkomunikasi dengan segmen pelanggannya dan menjangkau mereka untuk memberikan proposisi nilai. Saluran komunikasi, distribusi dan penjualan merupakan penghubung antara perusahaan dan pelanggan. Saluran adalah titik sentuh pelanggan yang sangat berperan dalam setiap kejadian yang mereka alami.

Revenue Streams (arus pendapatan): blok bangunan yang menggambarkan uang tunai yang dihasilkan perusahaan dari masing-masing segmen pelanggan (biaya harus mengurangi pendapatan untuk menghasilkan pemasukan). Jika pelanggan adalah inti dari model bisnis, arus pendapatan adalah urat nadinya.

Key Resources (sumber daya utama): blok bangunan yang menggambarkan aset-aset terpenting yang diperlukan agar sebuah model bisnis dapat berfungsi.

Key Partnerships (kemitraan utama): blok bangunan yang menggambarkan jaringan pemasok dan mitra yang membuat model bisnis dapat bekerja.

Cost Structure (struktur biaya): menggambarkan semua biaya yang dikeluarkan untuk mengoperasikan model bisnis. Blok bangunan ini menjelaskan biaya terpenting yang muncul ketika mengoperasikan model bisnis tertentu.

Analisis SWOT adalah identifikasi berbagai faktor secara sistematis untuk merumuskan strategi perusahaan. Analisis ini didasarkan pada logika yang dapat memaksimalkan kekuatan (Strengths) dan peluang (Opportunities), namun secara bersamaan dapat meminimalkan kelemahan (Weaknesses) dan ancaman (Threats) [5]. SWOT juga digunakan untuk menilai kekuatan-kekuatan dan kelemahankelemahan dari sumber daya yang dimiliki perusahaan dan kesempatan-kesempatan eksternal dan tantangan-tantangan yang dihadapi.

Analisis SWOT dapat digunakan dengan berbagai cara untuk meningkatkan analisis dalam usaha penetapan strategi. Umumnya yang sering digunakan adalah sebagai kerangka/ panduan sistematis dalam diskusi untuk membahas kondisi alternatif dasar yang mungkin menjadi pertimbangan perusahaan. Diagram analisis SWOT menjelaskan tentang bagaimana kombinasi strategi yang tepat dalam faktor internal dan faktor eksternal dalam kegiatan usaha, dibagi ke dalam beberapa kuadran.

Kuadran 1: ini merupakan situasi yang sangat menguntungkan perusahaan tersebut memiliki peluang dan kekuatan sehingga dapat memanfaatkan peluang yang ada. Strategi yang harus diterapkan dalam kondisi ini adalah mendukung kebijakan pertumbuhan yang agresif (Growth oriented strategy).

Kuadran 2: meskipun menghadapi berbagai ancaman, perusahaan ini masih memiliki kekuatan dari strategi internal. Strategi yang harus diterapkan adalah menggunakan kekuatan untuk memanfaatkan peluang jangka panjang dengan cara strategi diversifikasi (produk/ pasar).

Kuadran 3: perusahaan menghadapi peluang pasar yang sangat besar, tetapi di lain pihak, ia menghadapi beberapa kendala atau kelemahan internal. Fokus strategi perusahaan ini adalah meminimalkan masalah-masalah internal perusahaan sehingga dapat merebut peluang pasar yang lebih baik.

Kuadran 4: ini merupakan situasi yang sangat tidak menguntungkan, perusahaan tersebut menghadapi berbagai ancaman dan kelemahan internal.

Matriks IFAS dan EFAS adalah alat yang dipakai untuk menyusun faktor-faktor strategis perusahaan adalah matriks SWOT. Matriks ini dapat menggambarkan secara jelas bagaimana peluang dan ancaman eksternal yang dihadapi perusahaan agar dapat disesuaikan dengan kekuatan dan kelemahan yang dimilikinya. Matriks ini dapat menghasilkan empat set kemungkinan alternatif strategis. Empat kemungkinan alternatif strategi yang dapat disusun adalah sebagai berikut [5]:

1. Strategi SO: dibuat berdasarkan jalan pikiran perusahaan, yaitu dengan memanfaatkan seluruh kekuatan untuk merebut dan memanfaatkan peluang sebesar-besarnya. 
2. Strategi ST: strategi dalam menggunakan kekuatan yang dimiliki perusahaan untuk mengatasi ancaman.

3. Strategi WO: diterapkan berdasarkan pemanfaatan peluang yang ada dengan cara meminimalkan kelemahan yang ada.

4. Strategi WT: didasarkan pada kegiatan yang bersifat defensif dan berusaha meminimalkan kelemahan yang ada serta menghindari ancaman.

Business Model Canvas dapat menjadi tool yang sederhana guna menghasilkan alternatif strategi suatu usaha yang berujung pada kelayakan kualitas layanan, kompetensi sumber daya manusia, serta menunjang pencapaian jangka panjang perusahaan dengan lebih terukur [6]. Hasil penelitian lainnya mengatakan bahwa Business Model Canvas dapat digunakan dengan baik oleh bisnis ritel, menandakan bahwa Business Model Canvas dapat diterapkan di berbagai jenis usaha dan menjadi alternatif untuk menuju finansial yang sehat [7]. Hasil penelitian selanjutnya mengatakan dengan menggunakan analisis SWOT dapat melihat potensi kekuatan objek yang sedang diteliti dengan berupaya menangkap peluang yang ada. Kemudian mengkaji berbagai kelemahan, peluang dan tantangan yang ada sehingga menciptakan alternatif strategi yang dapat digukanakan untuk merencanakan strategi yang tepat untuk perusahaan [8]. Sedangkan penelitian yang akan dilakukan memastikan bahwa setiap fungsi komponen Business Model Canvas yang ada dalam perusahaan dapat berjalan dengan baik. Penggunaan Business Model Canvas dengan menggunakan analisis SWOT terhadap PT. Tolu diharapkan mampu merencanakan dan mengembangkan strategi bisnis untuk masa sekarang dan masa yang akan datang.

\section{METODE PENELITIAN}

Dengan metode ini Penulis bermaksud mengumpulkan data historis dan mengamati secara seksama mengenai aspek-aspek tertentu yang berkaitan dengan masalah yang sedang diteliti, sehingga akan memperoleh data yang dapat mendukung penyusunan laporan penelitian. Data yang digunakan dalam penelitian ini adalah data primer dan sekunder, data primer yaitu data yang didapat langsung dari sumber. Data yang diperoleh tersebut kemudian diproses dan dianalisis lebih lanjut dengan dasar teori yang telah dipelajari sehingga memperoleh gambaran mengenai objek tersebut dan dapat ditarik kesimpulan mengenai masalah yang diteliti. Data primer dalam penelitian ini diperoleh dari hasil wawancara yang kemudian diolah. Wawancara yang dilakukan bersifat wawancara semi-terstruktur dengan beberapa pertanyaan utama yang ditanyakan kepada responden dan terdapat beberapa pertanyaan tambahan apabila dibutuhkan. Sedangkan data sekunder akan diperoleh dari data pendukung lainnya berupa jurnal, artikel, laporan penelitian, buku dan sumber-sumber lainnya.

Teknik pengambilan data yang dilakukan dalam penelitian ini melalui purposive sampling, Penulis telah menentukan responden dari pihak perusahaan dengan kriteria merupakan top management atau middle management dan para karyawan di perusahaan. Pertimbangan pemilihan kriteria tersebut adalah responden/ narasumber mengerti dan memahami tujuan perusahaan jangka panjang serta kondisi eksisting dan capaian-capaian perusahaan sehingga dapat diketahui seberapa jauh usaha yang telah dilakukan oleh perusahaan. Narasumber dari penelitian ini adalah orang-orang yang menjabat sebagai Manajer ataupun Board of Directors di PT. Tolu. Sedangkan Responden dari penelitian ini adalah 100 karyawan yang bekerja di PT. Tolu.

Untuk teknik pengolahan data yang dilakukan pada penelitian ini mengacu pada beberapa hal sesuai dengan tahapan penelitian. Adapun analisis yang digunakan pada penelitian ini yakni analisis deskriptif kuantitatif, analisis Internal Factors Analysis Summary (IFAS) dan External Factors Analysis Summary (EFAS), analisis BMC dan analisis SWOT serta menggunakan Statistical Product and Service Solution (SPSS) untuk pengolahan datanya.

Dalam mengukur validitas data dengan menggunakan kuesioner yang dinilai dengan skala Likert, masing-masing dibuat dengan menggunakan skala 1 sampai 5 kategori jawaban, yang masing-masing jawaban diberi skor atau bobot yaitu banyaknya score antara 1 (STS) sampai 5 (SS) (Singarimbun, 1994).

Apabila data terkumpul, kemudian dilakukan pengolahan data, disajikan dan dianalisis. Dalam penelitian ini Penulis menggunakan uji statistik. Untuk menilai variabel $\mathrm{X}$ dan variabel $\mathrm{Y}$, maka analisis yang digunakan berdasarkan rata-rata (mean) dari masing-masing variabel. Nilai rata-rata (mean) ini diperoleh dengan menjumlahkan data keseluruhan dalam setiap variabel, kemudian dibagi 
dengan jumlah responden [9]. Selanjutnya menghitung persentasi efektivitas strategi dengan menggunakan rumus berikut.

$$
\text { Hasil }=\frac{\text { sskor }}{\text { skor maksimum }} \times 100
$$

Skor maksimum var $\mathrm{Y}=$ jumlah pernyataan (skor maksimal $\mathrm{x}$ total responden)

Skor maksimum var $\mathrm{Y}=27 \times 5 \times 100=13500$

Skor maksimum var $\mathrm{X}=$ jumlah pernyataan (skor maksimal $\mathrm{x}$ total responden)

Skor maksimum var $\mathrm{X}=6 \times 5 \times 100=3000$

Penyajian skala sesuai persentase total skor secara detil digambarkan seperti Gambar 2.

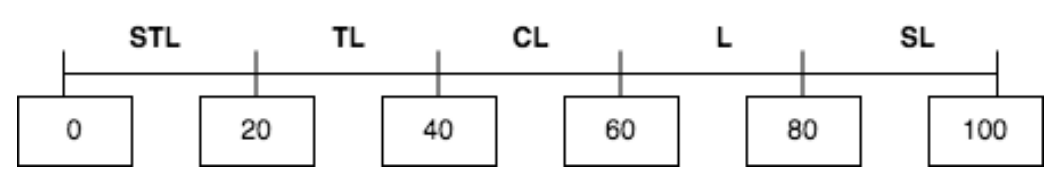

\section{Gambar 2. Persentase Kelayakan}

STL: Sangat tidak layak; TL: Tidak layak; CL: Cukup layak; L: Layak; SL: Sangat layak.

Selanjutnya akan dilakukan analisis terhadap hasil kuesioner yang telah diterima. Analisis data kuesioner ini menggunakan beberapa metode uji, yaitu uji validitas, uji reliabilitas dan analisis statistik deskriptif [10]. Metode uji ini menggunakan tool software SPSS.

Pada tahap uji validasi, menunjukkan sejauh mana skor/ nilai/ ukuran yang diperoleh benar-benar menyatakan hasil pengukuran/ pengamatan yang ingin diukur. Uji validitas dilakukan dengan mengukur korelasi antara variabel/ item dengan skor total variabel [11]. Validitas butir dapat diketahui dengan cara mengkorelasikan butir item dengan skor total responden. Untuk menunjukkan butir yang valid, dilakukan dengan membandingkan taraf signifikan (sig) dengan tingkat kesalahan (Alpha) yang ditentukan. Apabila taraf signifikan hitung lebih besar dari tingkat kesalahan (Sig > Alpha) maka item dianggap tidak valid, sedangkan apabila taraf signifikansi hitung lebih kecil dari tingkat kesalahan (sig Alpha) maka item dianggap valid.

Uji reliabilitas menunjukkan sejauh mana suatu alat pengukur dapat dipercaya atau dapat diandalkan. Setiap alat pengukur seharusnya memiliki kemampuan untuk memberikan hasil pengukuran relatif konsisten dari waktu ke waktu. Untuk mengetahui reliabilitas suatu alat ukur dapat dilihat dari koefisien reliabilitas instrumen, semakin tinggi koefisien tersebut maka semakin tinggi tingkat reliabilitas alat ukur tersebut, atau dapat dikelompokkan seperti tabel 1.

\section{Tabel 1. Tingkatan Reliabilitas}

\begin{tabular}{cl}
\hline Koefisien Reliabilitas & Tingkat Reliabilitas \\
\hline $0.00-0.20$ & Rendah Sekali \\
$0.20-0.40$ & Reandah \\
$0.40-0.60$ & Sedang \\
$0.60-0.80$ & Tinggi \\
$0.80-1.00$ & Sangat Tinggi \\
\hline
\end{tabular}

Dari kelima tingkat keandalan koefisien tersebut, yang digunakan sebagai indikator instrumen dikatakan reliabel adalah 0,60 sehingga instrumen dikatakan reliabel jika mempunyai tingkat keandalan koefisien $\geq 0,60$. 


\section{HASIL DAN PEMBAHASAN}

Berdasarkan hasil pengujian validitas yang dapat dilihat pada hasil pengolahan validitas SPSS yaitu nilai correct item total correlation terdapat 36 item $>0.3$, dinyatakan valid. Dari hasil uji validitas diketahui bahwa terdapat tiga item pernyataan yang tidak memenuhi syarat validitas. Nilai $r$ hitung sebesar -.520, -.075 dan .074 lebih kecil dan bernilai negatif dari $r$ tabel sebesar 0,3. Serta nilai signifikansi lebih dari 0,05 atau $5 \%$. Walaupun terdapat tiga item pernyataan yang tidak valid pengujian statistik masih dapat dilanjutkan ke uji reliabilitas dengan catatan tiga item pernyataan yang tidak valid tidak diikutsertakan dalam pengujian selanjutnya.

\section{Tabel 2. Reliability Statistics}

Cronbach's Alpha $\mathrm{N}$ of Items

\begin{tabular}{ll}
\hline .732 & 36 \\
\hline
\end{tabular}

Pada Tabel 2 Reliability Statistics, terdapat sebanyak 36 item mendapatkan nilai sebesar 0,732, lebih besar dari 0,60 sesuai dengan tingkat reliabilitas. Dengan demikian dapat dikatakan tingkat reliabilitas adalah tinggi.

Berdasarkan hasil analisis SWOT dapat dijelaskan strength (kekuatan) perusahaan memiliki desain yang up to date dan customize design diperkenankan, harga yang murah dan dapat bersaing serta produk furnitur yang berkualitas. Weakness (kelemahan) perusahaan adalah kurang luasnya daerah pemasaran produk, tenaga pemasaran yang kurang optimal dan tidak memiliki media untuk mempromosikan produk. Opportunity (peluang) perusahaan dapat membuka showroom di beberapa lokasi strategis, perkembangan teknologi informasi yang dapat dimanfaatkan untuk kegiatan pemasaran. Threat (ancaman) yang akan dihadapi perusahaan adalah keberadaan produk pesaing yang mengancam, keberadaan produk pengganti yang lebih murah, kebijakan pemerintah yang tidak membatasi masuknya pendatang baru. Hasil evaluasi model bisnis yang sedang dijalankan dengan metode analisis SWOT, didapatkan beberapa alternatif strategi yaitu strategi S-O fokus untuk memperkenalkan produk perusahaan dengan kualitas tinggi dan layanan pelayanan, membuat website untuk memasarkan produk, perluasan cabang agar dapat dijangkau masyarakat luas. Alternatif strategi W-O fokus pada memperluas jaringan distribusi dengan membuka showroom di daerah lain, merekrut tenaga kerja profesional. Alternatif strategi S-T fokus pada memberikan kualitas dan pelayanan yang baik, menjalin hubungan baik dengan para pemasok bahan baku. Alternatif strategi W-T fokus pada meningkatkan kapasitas produksi dan kualitas pelayanaan dalam mempromosikan produk.

Dari hasil analisis SWOT, di dalam perhitungan strateginya memerlukan penegasan dari adanya posisi dalam diagram Kartesius yaitu antara kekuatan dan kelemahan, maupun peluang dan ancaman yang kesemuanya digambarkan dalam garis-garis positif dan negatif. Dalam penentuan koordinat, dapat dilakukan berdasarkan perhitungan sebagai berikut:

1. Koordinat Analisis Internal (Skor total kekuatan-skor total kelemahan): $(3.68-1.65)=2.03$

2. Koordinat Analisis Eksternal (Skor total peluang-skor total ancaman): $(3.67-1.86)=1.81$

Berdasarkan hasil dapat ditentukan titik koordinat terletak pada $(2.03,1.81)$.

Dari perhitungan analisis tersebut diperoleh analisis internal/ IFAS adalah dengan kecenderungan nilai untuk faktor kekuatan dikarenakan nilai faktor kekuatan lebih besar dari nilai kelemahan sebesar 2.03. Nilai analisis eksternal/ EFAS adalah dengan kecenderungan nilai untuk faktor peluang lebih besar dari faktor ancaman yaitu sebesar 1.81 .

Nilai-nilai analisis baik internal dan eksternal tersebut dapat disajikan dalam bentuk diagram SWOT untuk menentukan posisi PT. Tolu Tiopan Tondi dalam industri sejenis. Gambar 3 berikut merupakan bentuk diagram SWOT PT. Tolu Tiopan Tondi. 


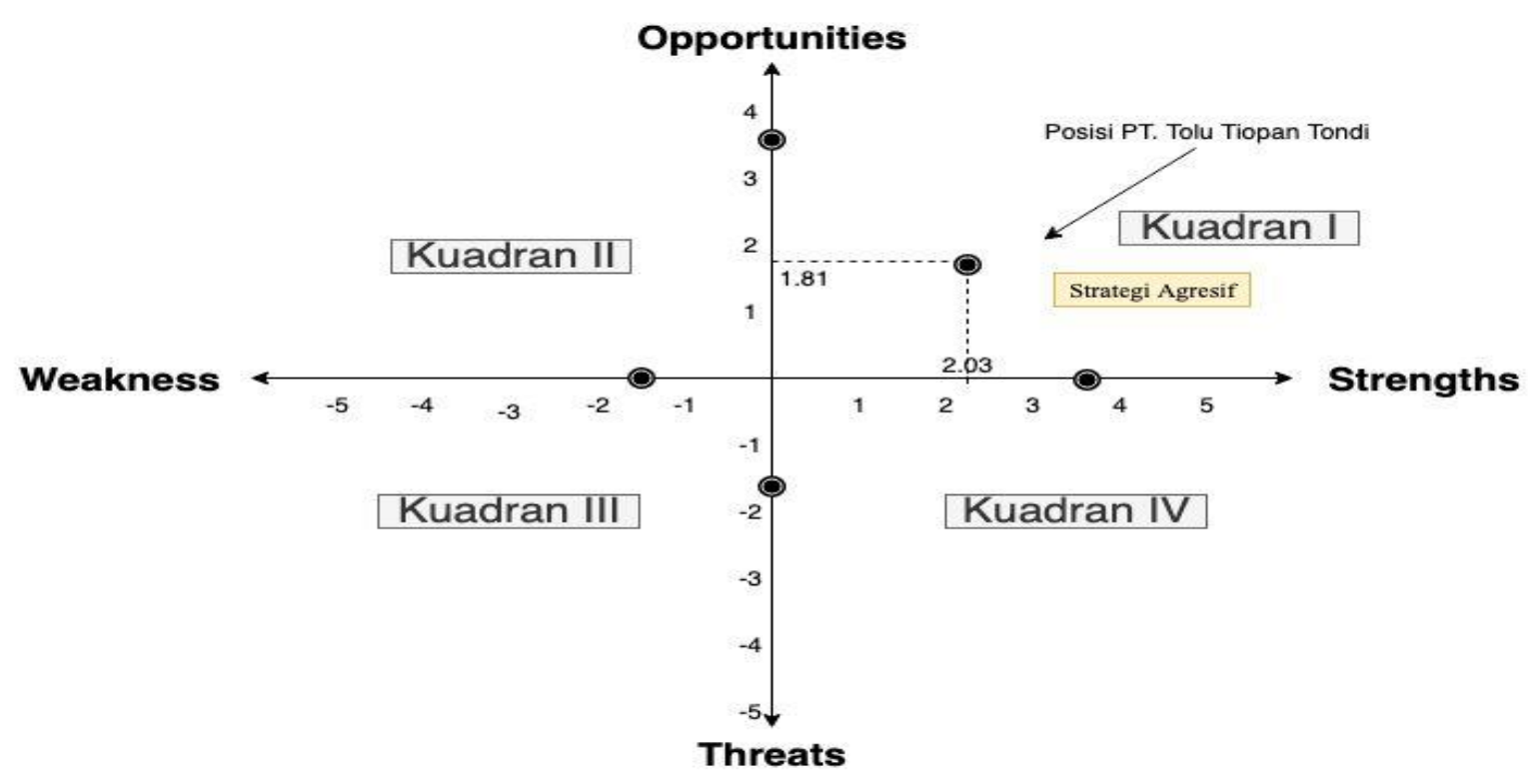

\section{Gambar 3. Diagram SWOT PT. Tolu}

Berdasarkan Gambar 3, terlihat bahwa posisi PT. Tolu Tiopan Tondi berada di dalam kuadran I. Posisi ini membuktikan bahwa PT. Tolu Tiopan Tondi merupakan organisasi yang kuat dan berpeluang, artinya organisasi dalam kondisi prima dan mantap sehingga benar-benar dimungkinkan untuk terus menjalankan ekspansi, memperbesar pertumbuhan dan meraih kemajuan secara maksimal. Tolu.

Gambar 4 berikut pengembangan strategi baru yang diusulkan untuk diimplementasikan oleh PT.

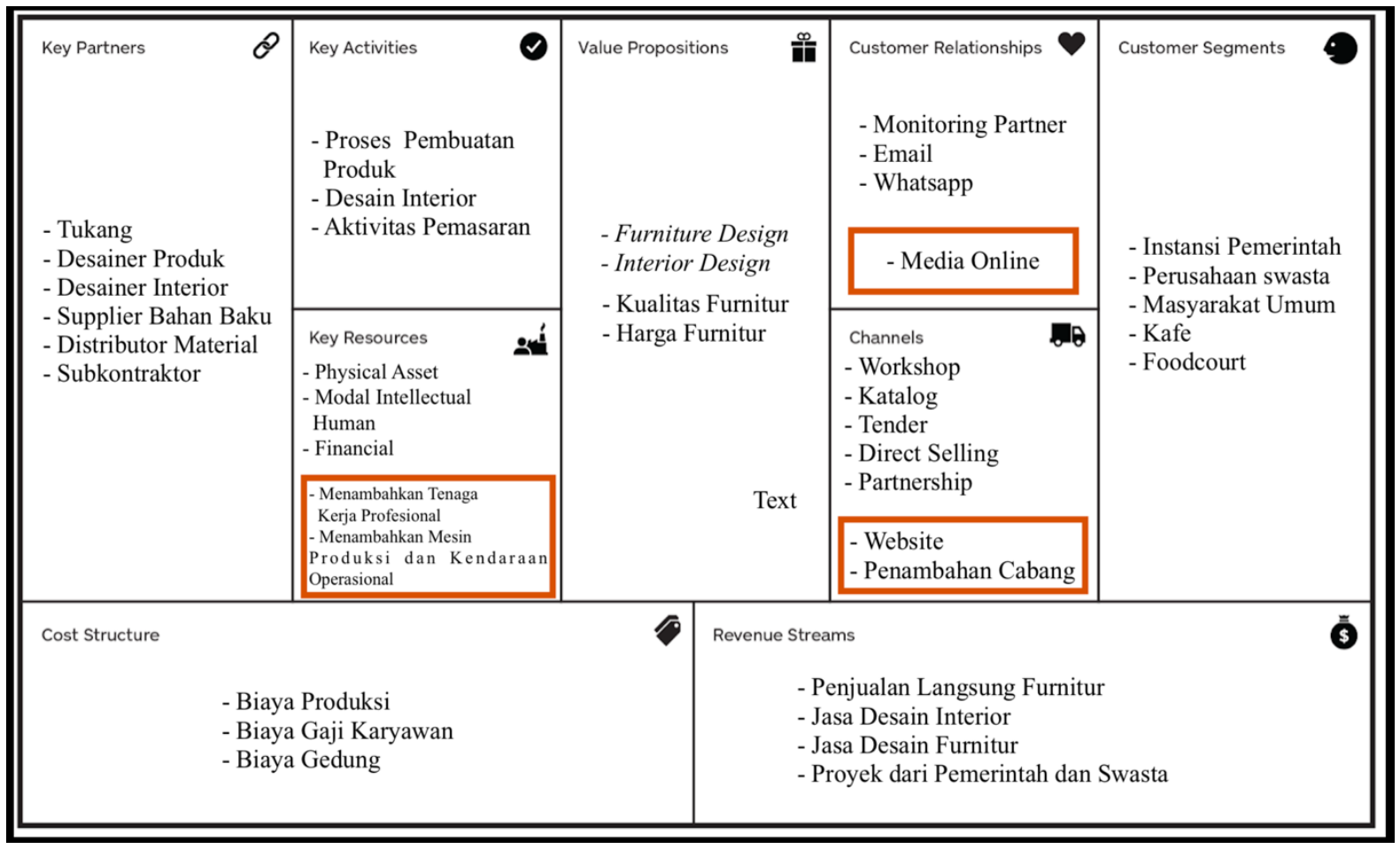

\section{Gambar 4. Strategi Business Model Canvas Baru PT. Tolu}

Berdasarkan hasil analisis ini, maka perlu dilakukan pengembangan pada model bisnis canvas yaitu pada komponen channel dengan menambahkan website untuk memasarkan produk agar lebih dikenal masyarakat luas dan memperluas cabang dengan lokasi strategis untuk menjangkau masyarakat luas. Pada komponen key resource dengan menambahkan tenaga kerja profesional dan 
beberapa physical asset untuk mempercepat pengerjaan proyek. Pada komponen customer relationship dengan menambahkan media online untuk meningkatkan kualitas pelayanan dalam mempromosikan produk atau layanan PT. Tolu.

\section{KESIMPULAN}

Pendekatan Business Model Canvas yang dilakukan pada kesembilan blok elemen untuk PT. Tolu meliputi customer segment, value proposition, channel, customer relationship, revenue stream, key activitiy, key resource, key partnership, dan cost structure. Setiap fungsi komponen Business Model Canvas yang ada dalam perusahaan sudah berjalan dengan baik. Dari sembilan elemen Business Model Canvas tersebut terdapat tiga elemen yang perlu dikembangkan. Ketiga elemen tersebut yaitu channel yaitu menambahkan website untuk melakukan proses pemasaran produk dan menambahkan cabang di beberapa lokasi strategis agar dapat menjangkau masyarakat luas; key resource yaitu dengan menambahkan tenaga kerja profesional dan menambahkan mesin produksi serta kendaraan operasional untuk meningkatkan performance perusahaan, dan customer relationship dengan menambahkan media online untuk menciptakan hubungan baik terhadap customer. Penggunaan Business Model Canvas dengan menggunakan analisis SWOT terhadap PT. Tolu dianggap mampu merencanakan dan mengembangkan strategi bisnis untuk masa sekarang dan masa yang akan datang.

\section{REFERENSI}

[1] BPS, “Tabel Perkembangan UMKM pada Periode 1997 -2013," Badan pusat statistic, 2016. https://www.bps.go.id/statictable/2014/01/30/1322/tabel-perkembangan-umkm-pada-periode1997--2013.html.

[2] A. Osterwalder, Y. Pigneur, A. Smith, and T. Movement, Osterwalder Pigneur 2009 business model generation. 2010.

[3] T. L. Wheelen, J. D. Hunger, K. E. Wheelen, and A. N. Hoffman, The Strategic Management and Business Policy TOWARD GLOBAL SUSTAINABILITY. 2016.

[4] P. Belton, Competitive Strategy: Techniques for Analyzing Industries and Competitors. 2017.

[5] F. Rangkuti, Teknik Membedah Kasus Bisnis Analisis SWOT Cara Perhitungan Bobot, Rating, dan OCAI. 2013.

[6] A. Wahyuni, H. Maupa, and H. Jusni, "Strategi Pengembangan Usaha Menggunakan Model Kanvas Pada Pt Nusantara Terminal Services Di Makassar,” pp. 65-80, 2017.

[7] S. A. B. HERAWATI NOVITHA, LINDRIATI TRIANA, "Penerapan Bisnis Model Kanvas dalam Penentuan Rencana ... Jurnal Agroteknologi Vol. 13 No. 01 (2019)," vol. 13, no. 01, p. 10, 2019, [Online]. Available: https://www.google.com.sg/url?sa=t\&rct=j\&q=\&esrc=s\&source=web\&cd=22\&ved=2ahUKE wiP6ITxiaXlAhWd6nMBHWxaASQ4FBAWMAF6BAgDEAI\&url=https\%3A\%2F\%2Fjurnal .unej.ac.id\%2Findex.php\%2FJAGT\%2Farticle\%2Fdownload\%2F8554\%2F6748\%2F\&usg=A OvVaw1Qb7cId3iNN0iHSKhF9BLV.

[8] B. B. Prasetyo, L. M. Baga, and L. N. Yuliati, "Strategi Pengembangan Bisnis Rhythm of Empowerment Dengan Pendekatan Model Bisnis Kanvas," J. Apl. Bisnis dan Manaj., vol. 4, no. 2, pp. 296-307, 2018, doi: 10.17358/jabm.4.2.296.

[9] Arikunto, "Suharsimi Arikunto.pdf," in Prosedur Penelitian Suatu Pendekatan Praktik-Revisi ke X, 2010.

[10] N. Martono, "Metode Penelitian Kuantitatif Analisis Isi dan Anlisis Data Sekunder," Ed. Revis i2, 2014.

[11] D. Risantono, "PERUSAHAAN DENGAN METODE ANALISIS SWOT DAN ANALISIS FAKTOR DI PERUSAHAAN RADIO PT . SUARA TIDAR SAKTI KOTA BATU,” pp. 242-250, 2017.

[12] A. Setiawan and M. Eka, "Analisis Bisnis Model Pada Driverbdg Menggunakan Pendekatan Business Model Canvas Business Model Analysis of Driverbdg Using Business Model," eProceeding Manag., vol. 4, no. 3, pp. 2968-2977, 2017.

[13] A. Wahyuni, H. Maupa, and H. Jusni, "Strategi Pengembangan Usaha Menggunakan Model Kanvas Pada Pt Nusantara Terminal Services Di Makassar," pp. 65-80, 2017. 
[14] H. Setyorini, M. Effendi, and I. Santoso, "Analisis Strategi Pemasaran Menggunakan Metode Quantitative Strategi Planning Matrix ( QSPM )," J. Teknol. dan Manaj. Agroindustri, vol. 5, no. 1, pp. 46-53, 2016, doi: 10.21776/ub.industria.2016.005.01.6.

[15] Sugiyono, "Metode Penelitian Kuantitatif, Kualitatif dan R \& D.Bandung:Alfabeta.," Metod. Penelitian Kuantitatif, Kualitatif dan $R$ D.BandungAlfabeta., 2012, doi: 10.1017/CBO9781107415324.004.

[16] Z. H. Siregar and S. E. Fitria, "Analisis Model Bisnis Dengan Menggunakan Pendekatan Business Model Canvas Terhadap Usaha Mikro Agribisnis Keramat Bey Berry Ciwidey," eProceedings Manag., vol. 3, no. 1, pp. 222-227, 2016, [Online]. Available: http://libraryeproceeding.telkomuniversity.ac.id/index.php/management/article/view/2849. 